\title{
Determination and Optimization of Feeding Device Parametres in the Plant for Preparing Liquid Feed Mixtures
}

\author{
Pavel Solonshchikov ${ }^{1}$, Peter Savinykh ${ }^{2},{ }^{*}$ Semjons Ivanovs ${ }^{3}$ \\ ${ }^{1}$ Vyatka State Agricultural Academy, Kirov, Russia \\ ${ }^{2}$ Federal Agrarian Scientific Centre of the North-East named after N.V. Rudnitsky, Russia \\ ${ }^{3}$ Latvia University of Life Sciences and Technologies, 2 Liela street, Jelgava, Latvia
}

\begin{abstract}
Feeding young animals is a very important stage during their growing-up period, but in order to provide them with essential nutrients, they are fed with liquid feeds, whole milk substitute in particular (WMS). The technique for reconstituting WMS consists of dissolving it in water followed by mixing, but it is significant to follow the cooking recipe strictly, so it is necessary to develop a system with a feeding (dosing) device that will make it possible to solve this problem. Theoretical and experimental studies of the feeding device have been conducted in order to optimize the technological process of mixing liquid feed. Theoretically, the quality of determining the mixture during dosing was established for the purpose of further research. The influence of the design and technological parameters of the feeding device was experimentally studied, and its efficiency was evaluated. It was found that as the inclination angle $\alpha$ increases from $67,5^{\circ}$ to $70^{\circ}$, the rotation speed $\mathrm{n}$ being from 850 to $1500 \mathrm{~min}^{-1}$, the maximum probability of staying in the tolerance field $\Delta P=96 \%$ is reached, and feed discharge $Q$ ranges from 540 to $660 \mathrm{~kg} \mathrm{~h}^{-1}$. The research makes it possible to develop a feeding device at the design stage, meeting the requirements of the recipe, having high discharge rates and the lowest energy consumption.
\end{abstract}

Keywords: component, efficiency, liquid feed, feeding device, mixture.

\section{Introduction}

The successful development of the agro-industrial complex consists of a well-established system of all technological processes. Currently, feeding farm animals is the most expensive part that forms the cost of production of milk and meat products, which directly affects the productivity and production life of the animal, depending on the cost of harvesting its own feed base and purchased feed components.

Analyzing the trends of technological features of feeding farm animals, more and more attention is paid to the use of energy and protein-rich, concentrated components enriched with mineral complexes, implemented as part of liquid feed mixtures (Kolesnikov, 2019).

Considering the issue of preparation and subsequent distribution of liquid feed mixtures for young stock (cattle, pigs, sheep, etc.), it should be noted that there is a certain formula for the final mixture. To maintain the required recipe of a particular composition or ratio, it is necessary to meet zootechnical requirements, which are of determinative character. Thus, it is necessary to design and develop such machines and devices that could meet these needs, but at the same time be universal, taking into account current requirements and trends in technology development (Solonshchikov, 2018; Golubkov, Fyodorov, \& Antonov, 2020; Kolesnikov, 2019; Ferhoyl, 2009).

The most common structure of any liquid feed mixture is the presence of two components: solid and liquid ones, and the ratio of each of them should be different depending on the recipe. Then the components are to be mixed. The liquid component has such properties that make it easy to adjust the volume by filling the space completely. In turn, it is not always possible to feed a solid component accurately into the

\footnotetext{
* Corresponding Author's email: semjons@apollo.lv
} 
mixing zone due to its properties such as density, humidity, flowing ability, caking ability, etc. Therefore, the accuracy of its discharge will ultimately affect the quality of the mixture in general.

The loading uniformity in the working chamber (mixing unit) has a significant effect on the indicators of the subsequent mixing process. Therefore, the issue of metered flow of powdered material to the working chamber deserves much attention (Vedishchev et al., 2019 a); Savinyh et al., 2019; Chzhao, Zhavner M., \& Zhavner V., 2019).

Dosing devices for bulky materials on the principle of dosing are divided into weight batchers and volume batchers. According to the parameters of the feed flow, there are dosers of continuous action (belt, plate, slotted, vibrating, disc-shaped), pulsating (screw, drum, scraper, chain-washer, blade) and periodic action (plunger, pendulum, bucket, etc.). According to the method of moving the material in the dispenser, they can be divided into gravitational (slotted, vibrating, bucket, pendulum and batch meters) and forced (all the rest, except the above five) (Kolesnikov, 2019).

There are three ways to regulate the efficiency of the batcher: speed, flow cross-section, and frequency of serving.

\section{Materials and Methods}

In general, the process of continuous feed dosing consists in providing a continuous flow of a certain amount of material through the holes at a certain speed. It is necessary to monitor and register the current flow values (discharge rates), as well as integrate the values over time in order to estimate the amount feed delivered. Thus, to predict the accuracy of the recipe for liquid feed mixture, it is necessary to assume the following ratios (Vedishchev et al., 2019 b; Burdo et al., 2017).

$$
\begin{gathered}
\left|Q_{n}^{*}-Q^{*}\right| \leq \Delta ; \\
Q_{i}<Q ; \\
\sum_{i=1}^{n} q_{i}=Q_{0},
\end{gathered}
$$

where $Q_{n}^{*}$ - predicted average value of the controlled $Q_{i}$ indicator in the mixture;

$Q^{*}{ }_{c p}-$ actual average value of the controlled $Q_{i}$ indicator in the mixture;

$\Delta$ - acceptable deviation of the controlled $Q_{i}$ indicator in the mixture;

$q i$ - consumption of $i$ - feed;

$n$-amount of feed in the ration.

The content of the controlled indicator $Q_{i}$ in the mixture can be determined as:

$$
Q_{n}^{*}=\frac{\sum_{i=1}^{n} Q_{i}^{*} \cdot q_{i}}{Q_{0}}
$$

where $Q_{1}^{*}$ - predicted content controlled by the indicator in volume $q_{i}$;

$$
Q_{0} \text { - predicted volume of feed mixture. }
$$

The optimal formulation of the mixture should provide a maximum or minimum of some target function or coefficient:

$$
f\left(q_{i_{1}}, q_{i_{1}}, q_{i_{1}}, \ldots q_{i_{n}}\right) \rightarrow k_{\min (\max )}
$$

In the formulations of liquid feed mixtures, it is common to use the following ratios of solid (powdery) and liquid components, namely 1: $8 \ldots 1: 9$, which can be expressed in terms of the coefficient obtained in the formula and written as follows (5):

$$
k_{\min (\max )}=\frac{Q_{s}}{Q_{l}}=\left(\frac{1}{8} \ldots \frac{1}{10}\right)
$$

where $Q_{s}$ and $Q_{l}$ - the amount of solid (powdery) and liquid components respectively.

Thus, it has been found that feeding involves changes in this coefficient depending on the ratios, or the value is equal to $0.1 \ldots 0.125$.

Taking into account the previously stated assumptions, it is necessary to develop a plant that could combine the functions of a dosing device with subsequent mixing of components.

On the basis of the analysis performed and the state of technology, a scheme for the preparation of liquid feed mixtures is proposed (Figure 1).

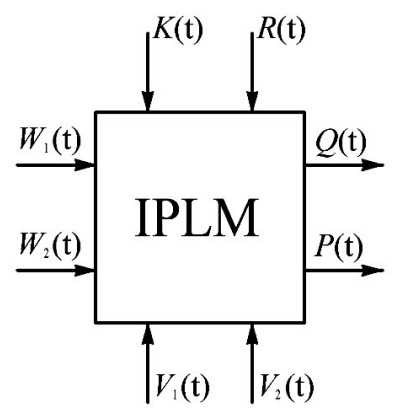

Figure 1. Flow diagram of the plant for preparing liquid feed mixtures (PPLFM).

According to this scheme, all the variables which are included in the plant are singled out and deciphered: properties of both media $V_{I}(\mathrm{t})$ and $V_{2}(\mathrm{t})$, discharge of components $W_{l}(\mathrm{t})$ and $W_{2}(\mathrm{t})$, constructive $K(\mathrm{t})$ and process $R(\mathrm{t})$ parameters, respectively the output parameters of the system are $Q(\mathrm{t})$ the discharge of component or operational parameters and the 
quality of the mixture $P(\mathrm{t})$ or performance parameters (coefficient of variation $v$, and the probability of being within tolerance limit $\Delta P$ ).

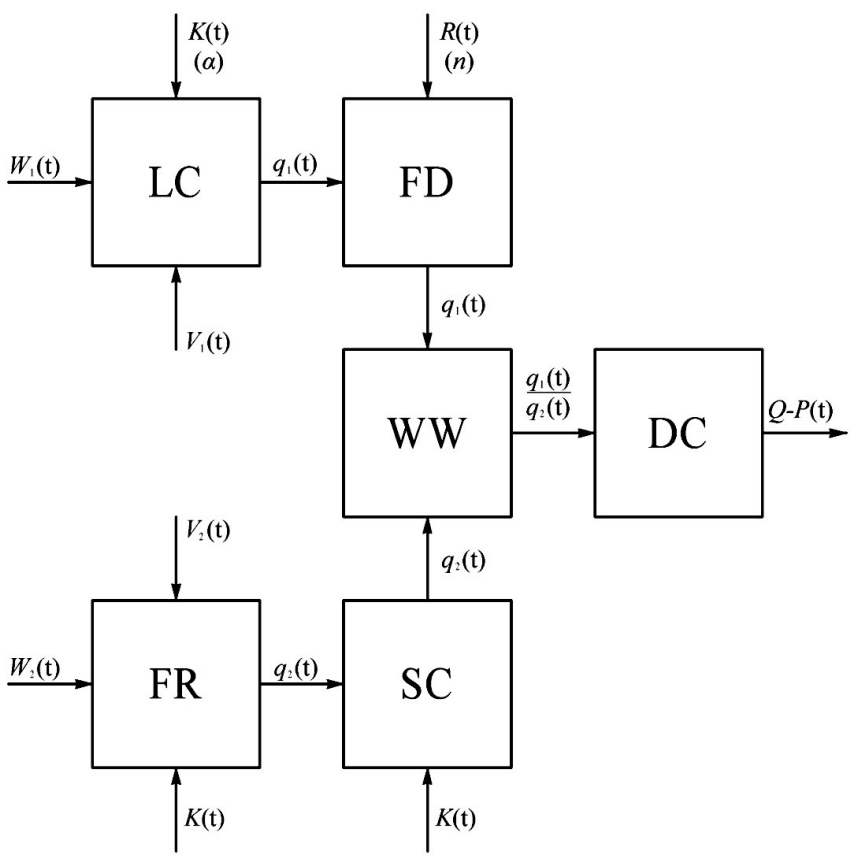

Figure 2. Flow diagram of operating PPLFM: LC - load chamber (hopper); FD - feeding device; WW - working chamber; FR - feed reservoir; SC - suction connector; DC - discharge connector.

As one can see from the diagram, each component is located in its own storage tank. Flow $q_{l}(\mathrm{t})-$ the solid component can be weighed initially, taking into account the volume of the loading chamber, and the liquid $q_{2}(\mathrm{t})$ located in the tank must have such a discharge which could preserve the recipe, but generally, the feed delivery must be large due to feeding conditions, since there is a need for transportation or processing large volumes. Therefore, sometimes it is better not to regulate the fluid flow but to leave it as it is, for the subsequent use of the plant as a pump, but it is better to have the dimensions of the suction and

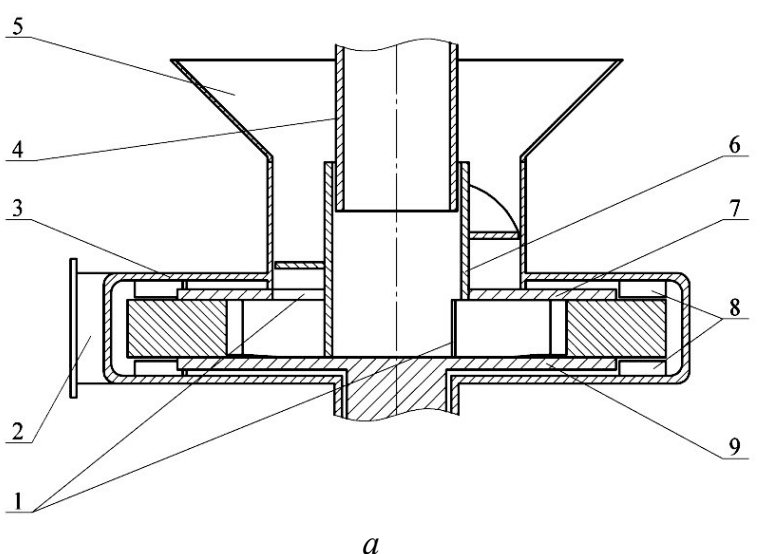

Considering each element of the plant, one can see the following (Figure 2). 
et al., 2014; Mokhnatkin, Filinkov, \& Solonschchikov, 2015; Lyalin et al., 2019; Solonshchikov, 2016; Solonshchikov, 2018; Chzhao et al., 2019; Berger, 2010).

The plant consists of a window 1, a discharge pipe 2 , a working chamber 3 in which there are blades 8 and an impeller consisting of the main disc 9 and a cover disk 7 fixed. The impeller and fixed blades interact to mix the components. On the cover disk, there is a bush 6 that performs the function of a feeding device that moves the material from the loading chamber 5 to the inter-blade channels of the impeller, so the rotation frequency of the impeller and the feeding device are the same, and they will have the same drive.
Therefore, it is necessary to justify the parameters of the feeding device with the design parameters of the loading chamber (inclination angle $\alpha$ degrees), which must be within the dimensions of the plant. To study the batching process, it was necessary to develop a stand (Figure 4), which made it possible to change rotational speed ( $\mathrm{n}$ ) by changing pulleys, and the angle of the load chamber was also changed (Gerdt, 2019; Vedishchev et al., 2019 a).

Rotational speed was controlled by a tachometer IT 5-ChM, "Termite", the samples were weighed on the scales "Mera" VM-2/3, experiment time was measured with a stopwatch SDS-pr1.

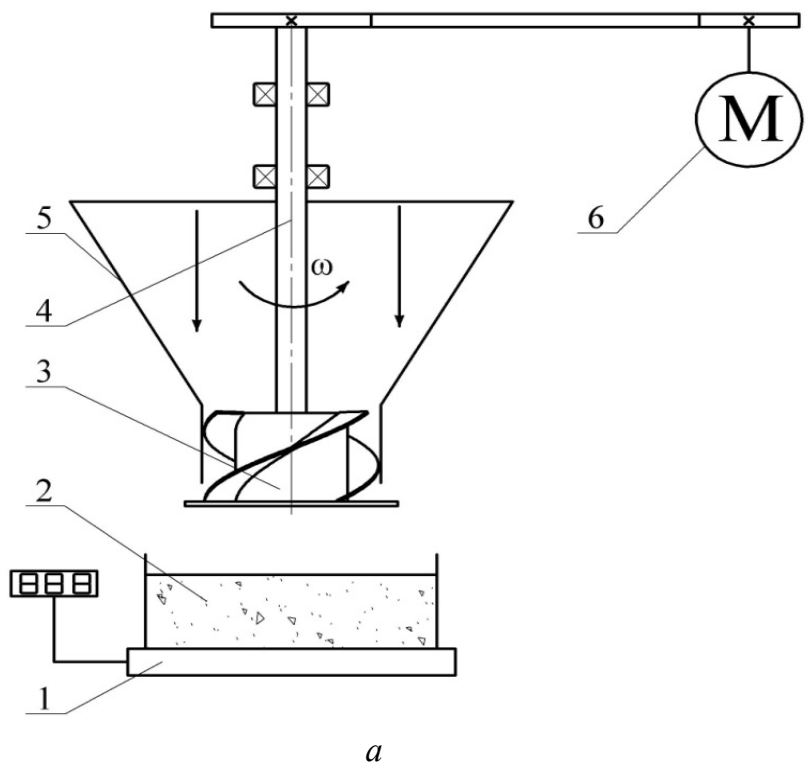

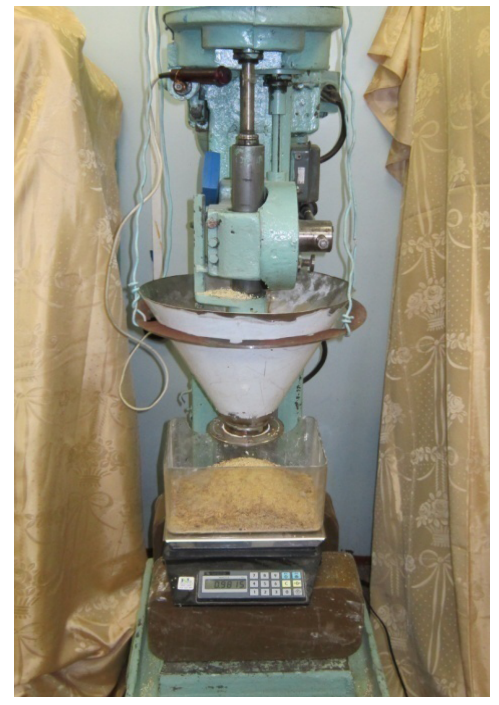

$b$

Figure 4. Scheme (a) and general outline (b) of the stand for determining the discharge of the feeding device: 1 - electronic scales; 2 - container for sampling; 3 - feeding device; 4 -drive shaft; 5 - load chamber; 6 - electric motor.

\section{Results and Discussion}

The factors were the speed of rotation $n$ and the inclination angle of the loading chamber $\alpha$. The angles of inclination corresponded to $60^{\circ}, 65^{\circ}$ and $70^{\circ}$, considering that the upper part of the loading chamber should have dimensions equal to the diameter of the motor flange, and the height is selected, accordingly.

Figure 5 presents the dependence of the bulk component discharge on the rotation frequency of the helically wound bushing and the inclination angle of the loading chamber, which clearly shows that the increase in the inclination angle of the loading compartment and rotational speed increases the flow in direct proportion.

Determining the dependence of the relative error indicator of the dosing device (coefficient of variation), we obtain the following dependence (Figure 6).
Analyzing this relationship, one can say that as the angle of inclination increases, the dosage error will be decreased. The dependences of the probability of the dosing process staying in the set tolerance field on the inclination angle and rotation speed of the helically wound bushing are shown in Figure 7.

Studies have shown that in the speed range from 1000 to $1300 \mathrm{~min}^{-1}$ at the inclination angles of the loading chamber equal to $65^{\circ}$ and $70^{\circ}$, the probability $\Delta P$ is within $95 \%$. If the frequency is increased, only at the angle of $70^{\circ}$ the value of $\Delta P$ will remain the highest. Thus, having conducted one-factor experiments to determine the effectiveness of the dosing device, one can identify the main factor that affects the dosing process - the angle of the loading chamber $\alpha$.

To study the mutual influence of the inclination angle of the loading chamber and the rotation speed of 
the helically wound bushing $\mathrm{n}$ on three optimization $3 \times 2$ matrix is implemented (table 1). This plan is applied criteria: feed $Q, \mathrm{~kg} \cdot \mathrm{h}^{-1}$, coefficient of variation $v, \%$; if it is necessary to study factors at different levels probability of staying in the tolerance field $\Delta P, \%$, a (Gerdt, 2019).

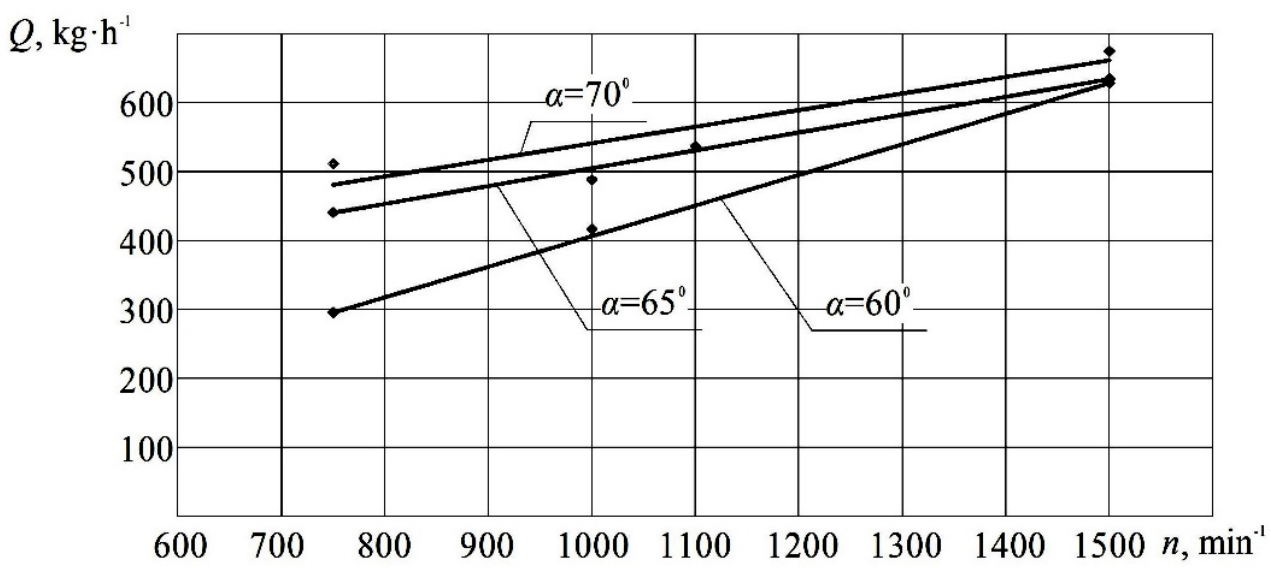

Figure 5. Dependence of bulk component discharge $Q, \mathrm{~kg} \cdot \mathrm{h}^{-1}$ on rotation speed of the impeller $\mathrm{n}$ and inclination angle of the load chamber $\alpha$.

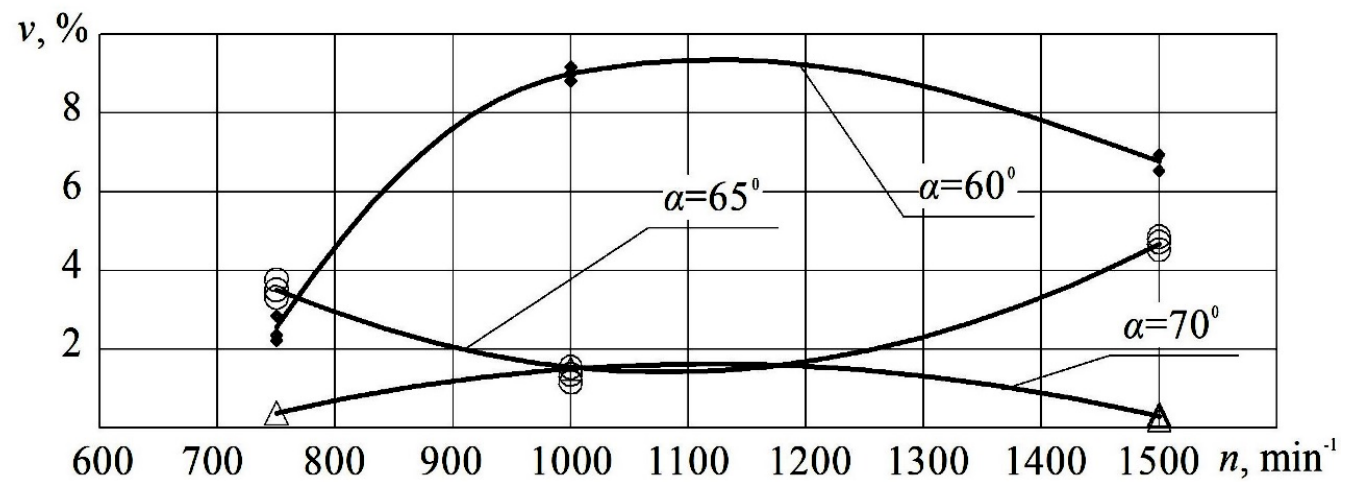

Figure 6. Dependence of the coefficient of variation $v, \%$ of bulk components on the rotation speed of the impeller $\mathrm{n}$ and the inclination angle of the loading chamber $\alpha$.

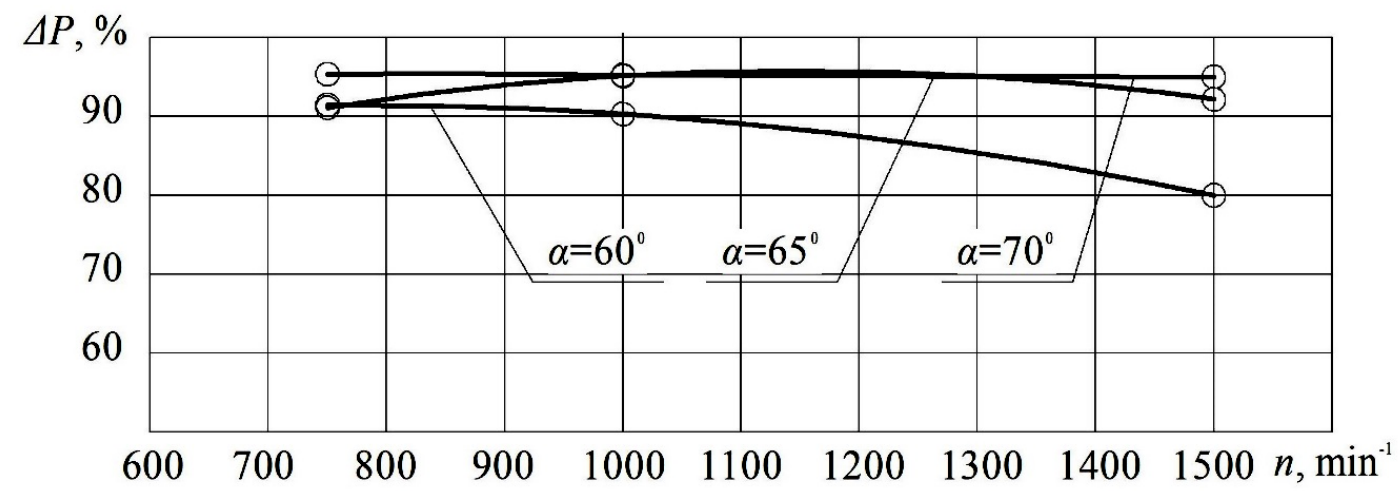

Figure 7. Dependence of probability of the dosing process staying in the set tolerance field $\Delta P$, $\%$ on the speed of the impeller $\mathrm{n}$ and the inclination angle of the loading chamber $\alpha$. 


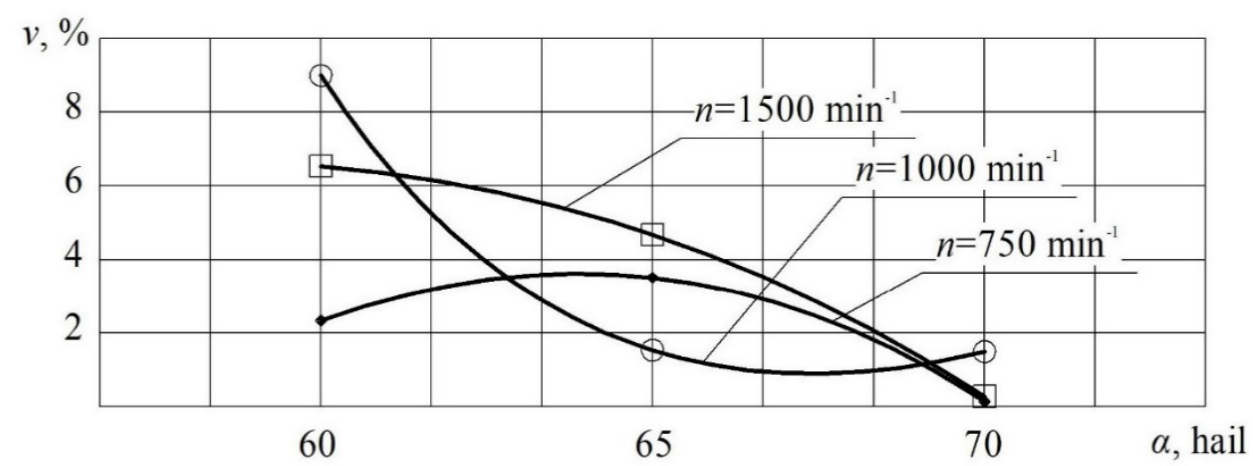

Figure 8. Dependence of variation coefficient $v, \%$ on the rotation speed of the impeller $\mathrm{n}$ and the inclination angle of the loading chamber $\alpha$.

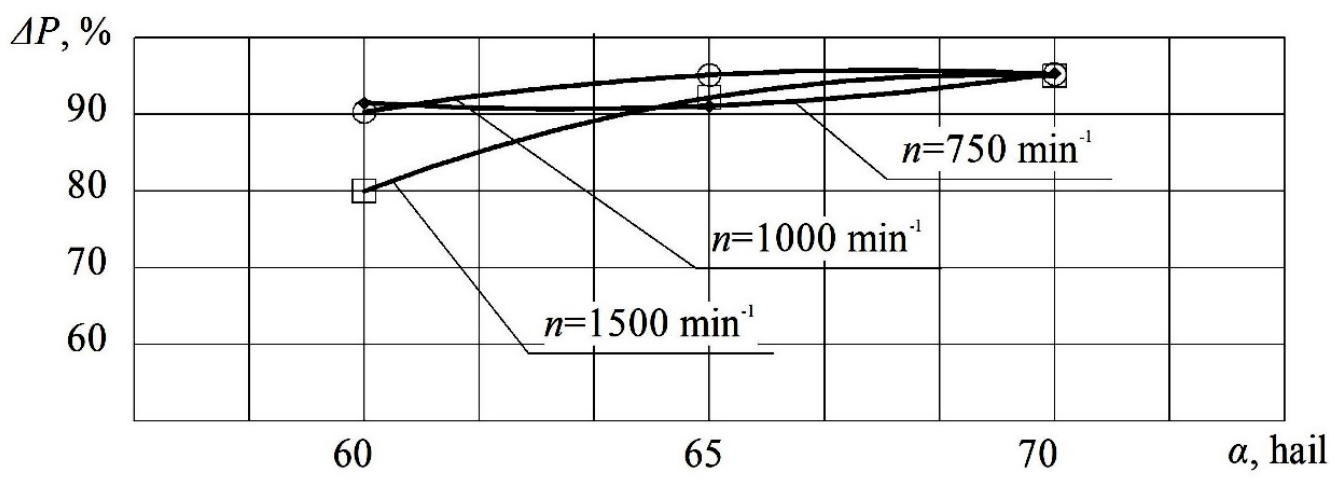

Figure 9. Dependence of the probability of the technological dosing process staying in the set tolerance field $\Delta P \%$ on the rotation speed of the impeller $\mathrm{n}$ and the inclination angle of the loading chamber $\alpha$.

Table 1

The influence of the inclination angle of the loading chamber $(\alpha)$ and rotation speed $(n)$ on feed discharge $(Q)$, coefficient of variation $(v)$ and the probability of staying in the field of tolerance $(\triangle P)$

\begin{tabular}{|c|c|c|c|c|c|}
\hline \multirow{3}{*}{$\begin{array}{l}\text { Levels of factor } \\
\text { variation }\end{array}$} & \multicolumn{2}{|c|}{ Factors } & \multicolumn{3}{|c|}{ Optimization criteria } \\
\hline & $\begin{array}{c}\text { Inclination angle } \\
\text { of the load } \\
\text { hopper } \alpha \text {, degrees }\end{array}$ & $\begin{array}{l}\text { Shaft rotation } \\
\text { frequency } \\
\mathrm{n}, \mathrm{min}^{-1}\end{array}$ & $\begin{array}{c}\text { Feed } \\
\text { discharge, } \\
Q, \mathrm{~kg} \mathrm{~h}^{-1}\end{array}$ & $\begin{array}{c}\text { Variation } \\
\text { coefficient, } \\
v, \%\end{array}$ & $\begin{array}{c}\text { Staying in the } \\
\text { tolerance field, } \\
\Delta P, \%\end{array}$ \\
\hline & $x_{1}$ & $x_{2}$ & $y_{1}$ & $y_{2}$ & $y_{3}$ \\
\hline Upper level (+) & 70 & 1500 & - & - & - \\
\hline Base level (0) & 65 & - & - & - & - \\
\hline Lower level (-) & 60 & 750 & - & - & - \\
\hline \multicolumn{6}{|l|}{ Experiments } \\
\hline 1 & -1 & -1 & 296.0 & 2.35 & 91.4 \\
\hline 2 & -1 & -1 & 629.1 & 6.54 & 80.0 \\
\hline 3 & 0 & -1 & 441.1 & 3.51 & 91.0 \\
\hline 4 & 0 & +1 & 643.6 & 4.68 & 92.1 \\
\hline 5 & +1 & -1 & 512.8 & 0.14 & 95.3 \\
\hline 6 & +1 & +1 & 675.0 & 0.28 & 95.0 \\
\hline
\end{tabular}


After implementing the experiments and calculating the regression coefficients, the following mathematical models of the dosing device workflow were obtained: $y_{1}=537.89+65.65 \cdot x_{1}+114.79 \cdot x_{2}-9.63 \cdot x_{1}^{2}-42.75 \cdot x_{1} \cdot x_{2}$, $y_{2}=4.09-2.11 \cdot x_{1}+0.91 \cdot x_{2}-1.76 \cdot x_{1}^{2}-1.01 \cdot x_{1} \cdot x_{2}$,

$y_{3}=91.59+25.29 \cdot x_{1}+11.93 \cdot x_{2}-21.73 \cdot x_{1}^{2}-17.79 \cdot x_{1} \cdot x_{2}$,

Analysis of the mathematical model for $y_{1}(7)$ showed that in this series of experiments, the flow rate
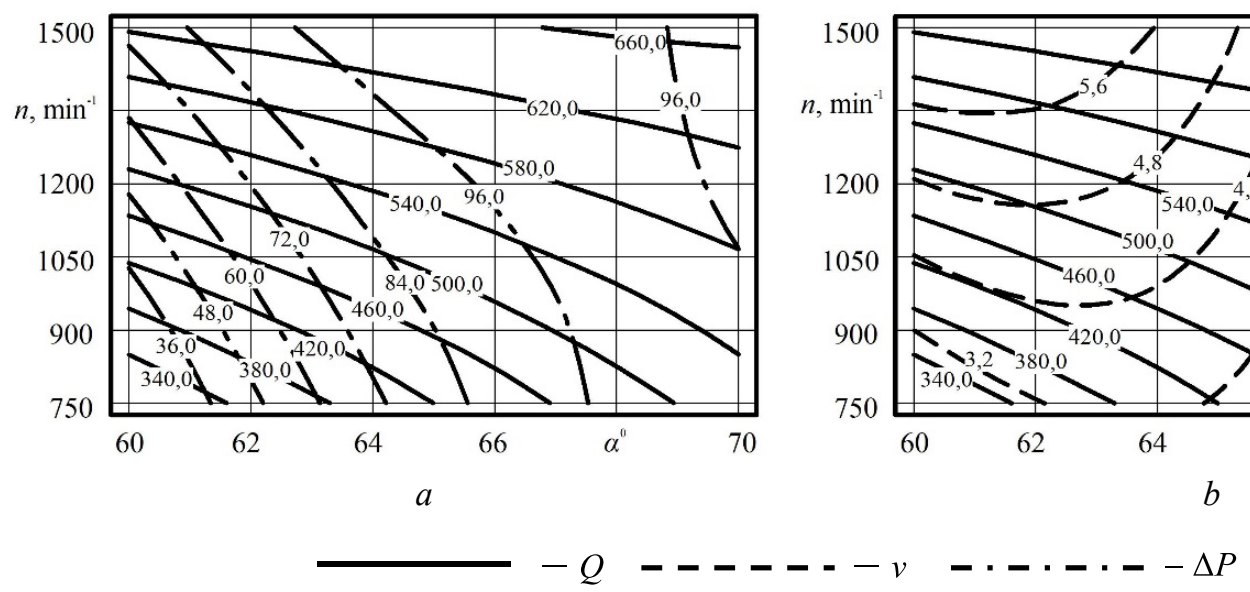

$\mathrm{a}$ - for criteria $y_{1}$ and $y_{2} ; \mathrm{b}$ - for criteria $y_{1}$ and $y_{3}$

Figure 10. Two-dimension cross-sections of response surfaces for evaluating the influence of the loading chamber inclination angle $(\alpha)$ and shaft speed $(n)$.

The increase in the probabilities of staying in the tolerance field $\Delta P$ described by the equation $y_{3}(9)$ shows that in this series of experiments, the predominant influence is exerted by the inclination angle of the loading compartment $\left(b_{1}=25.29\right)$.

Two-dimension section (Figure $10 a$ ) in the coordinates of the loading compartment inclination angle $\alpha 0$, and the frequency of rotation of the impeller $\mathrm{n}, \mathrm{min}^{-1}$ shows that the increase in angle $\alpha$ from $67^{0}$ to $70^{\circ}$ and rotational speed of the impeller $n$ from 1350 to $1500 \mathrm{~min}^{-1}$ results in maximum discharge.

Analysis of the two-dimension cross section (Figure 10, b) in the coordinates of the inclination angle of the loading chamber $\alpha^{0}$, and the rotation speed of the impeller $n$, min- 1 shows that when the angle of inclination $\alpha$ increases from $67,5^{\circ}$ to $70^{\circ}$ and at the speed $\mathrm{n}$ from $85^{0}$ to $1500 \mathrm{~min}^{-1}$, the maximum probability of staying in the tolerance field $\Delta P=96 \%$ is reached, and the discharge rate $Q$ will range from 540 to $660 \mathrm{~kg} \cdot \mathrm{h}^{-1}$.

\section{Conclusion}

The design and technological scheme of the plant for preparation of liquid feed mixtures (PPLFM) have been developed, and it combines the functions of a

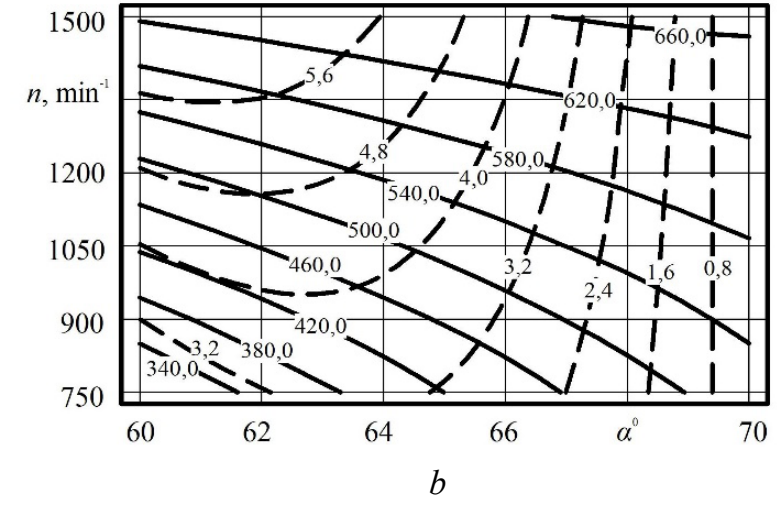

is predominantly affected by the rotation speed of the impeller $\left(b_{2}=114.79\right)$, to somewhat smaller extent - by the inclination angle of the loading hopper $\left(b_{1}=65.65\right)$.

The mathematical model $y_{2}(8)$ shows that in this series of experiments, the value of the variation coefficient is mostly influenced by the inclination angle of the loading chamber $\left(b_{1}=-2.11\right)$.

In this case, the coefficient of variation $\mathrm{v}$ will decrease in the range from 3.2 to $0.8 \%$.

dispenser, pump and mixer. Experimental studies have confirmed the effectiveness of the feeding device operating together with the main working units.

The optimal values of the feeding device will be as follows: the discharge $Q$ is $540 \ldots 660 \mathrm{~kg} \cdot \mathrm{h}^{-1}$, the inclination angle of the loading chamber $\alpha$ corresponds to $67.5^{\circ}$ to $70^{\circ}$, while the probability of staying in the tolerance field will be $\Delta P=96 \%$, which meets the requirements for dosing.

\section{References}

Berger, D. (2010). Gesundes aus der Kiste (Healthy food out of the box). DZL. No 2, pp. 15-18. (in German).

Burdo, O., Bandura, V., Kolianovska, L., Dukulis, I. (2017). Experimental research of oil extraction from canola by using microwave technology. Engineering for Rural Development, Vol. 16, pp.296-302.

Chzhao, V., Zhavner, M.V., Zhavner, V.L. (2019). Universal dispensers for small businesses of food industry. Scientific Journal NRU ITMO. Series: Processes and Food Production Equipment. No 2, pp. 19-26.

Ferhoyl, I. (2009). Gutes Kolostrum wirkt ein Leben 
lang (Good colostrum lasts a lifetime). DZL. No 8. pp. 22-24. (in German)

Gerdt, A. (2019). Feeders and batchers for bulk materials. Youth and Science, No 3. p. 59.

Golubkov, A., Fyodorov, O., Antonov, A. (2020). On the issues of dosing bulky components of mixed feeds. Scientific support for engineering and technical system of agroindustrial complex: challenges and opportunities. Proceedings of the National scientific and practical conference devoted to the $60^{\text {th }}$ anniversary of the Automobile Maintenance and Repair Department of the Agroengineering Faculty, Kirov, pp. 23-26.

Kolesnikov, A. (2019). Experimental studies on performance efficiency of liquid batch mixer. Innovations in Agroindustrial complex: challenges and opportunities. No 2 (22). pp. 37-49.

Lyalin, Ye.A., Trutnev, M.A., Trutnev, N.V. (2019). Evaluating the performance efficiency of feed distributor with helical dispenser under operating conditions. Perm Agrarian Herald. 2019. No 4 (28). pp. 4-10.

Mokhnatkin, V., Filinkov, A., Solonshchikov, P. (2015). Selecting rational parameters for the feeding device of the plant for preparing feed mixtures. Tractors and Agricultural Machinery. No 4, pp. 45-47.

Mokhnatkin, V., Shulyatyev, V., Filinkov, A., Solonshchikov, P. (2014). Plant for preparing mixtures. Utility model patent RU 146974.

Savinyh, P., Kazakov, V., Moshonkin, A., Ivanovs, S. (2019). Investigations in feeding device of grain crusher. Engineering for Rural Development,
Vol.19, pp. 123-128.

Solonshchikov, P. (2018). Studies and evaluation of operational reliability of the plant for preparing mixtures in operation. Energy-saving agricultural technologies and equipment for Northern agriculture and animal husbandry. Monograph under general editorship of V.Sysuev. Kirov: "Kirov Regional Printing House" ltd., pp. 306 - 313.

Solonshchikov, P. (2016). Wpływ trybu pracy instalacji do przygotowania mieszanek na wskaźnik kompletności rozpuszczenia. Problemy intensyfikacji produkci zwierzecej z uwzglednieniem poprawy struktury obszarowej gospodarstw rodzinnych, ochrony srodowiska. (Influence of the operation mode of the installation for preparation of mixtures on the indicator of complete dissolution. Problems of the intensification of animal production, taking into account the improvement of the area structure of family farms, environmental protection). Monografia. Falenty - Warszawa, pp. 232-234. (in Polish).

Vedishchev, S., Prokhorov, A., Zavrazhnov, A., Kholyshev, N., Kazhiyakhmetova, K. (2019 a). Research into energy consumption of the screw batch mixer. Herald of Ryazan State Agrotechnological University named after P. Kostychev. No 2 (42), pp. 96-101.

Vedishchev, S., Zavrazhnov, A., Prokhorov, A., Kapustin, V., Zazulya, A. (2019 b). Batch mixers of dry bulky feeds. Industry and Agriculture, No 12 (17). pp. 10-14. 